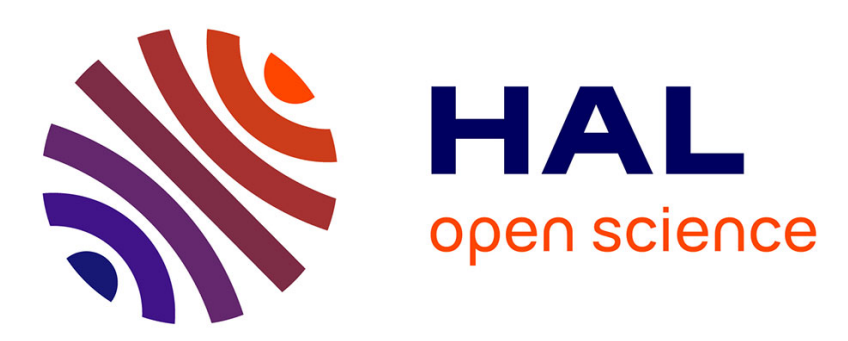

\title{
Influence of abrasive water jet parameters on the surface integrity of Inconel 718
}

\author{
Lorena Cano Salinas, Kamel Moussaoui, Akshay Hejjaji, Mehdi Salem, Anis
} Hor, Redouane Zitoune

\section{- To cite this version:}

Lorena Cano Salinas, Kamel Moussaoui, Akshay Hejjaji, Mehdi Salem, Anis Hor, et al.. Influence of abrasive water jet parameters on the surface integrity of Inconel 718. International Journal of Advanced Manufacturing Technology, 2021, 114, pp.997-1009. 10.1007/s00170-021-06888-9 . hal03201744

\section{HAL Id: hal-03201744 https://imt-mines-albi.hal.science/hal-03201744}

Submitted on 23 Apr 2021

HAL is a multi-disciplinary open access archive for the deposit and dissemination of scientific research documents, whether they are published or not. The documents may come from teaching and research institutions in France or abroad, or from public or private research centers.
L'archive ouverte pluridisciplinaire HAL, est destinée au dépôt et à la diffusion de documents scientifiques de niveau recherche, publiés ou non, émanant des établissements d'enseignement et de recherche français ou étrangers, des laboratoires publics ou privés. 


\title{
Influence of abrasive water jet parameters on the surface integrity of Inconel 718
}

\author{
Lorena Cano Salinas ${ }^{1} \cdot$ Kamel Moussaoui $^{1} \cdot$ Akshay Hejjaji $^{1} \cdot$ Mehdi Salem $^{2} \cdot$ Anis Hor $^{1} \cdot$ Redouane Zitoune $^{1}$ (D)
}

\begin{abstract}
Inconel 718 (IN718) is a precipitation hardened nickel-base super-alloy exhibiting high strength and good corrosion resistance at elevated temperatures and on the downside; it is characterized by poor machinability. Abrasive water jet (AWJ) process offers a potential method to machining difficult-to-cut materials such as IN718. The present work investigates the influence of AWJ parameters on surface roughness, topography, depth of cut, and residual stress when milling IN718. Surface characterization was conducted through 3D optical microscopy and SEM techniques. Residual stresses were measured in longitudinal and transverse directions with respect to the machining path using X-ray diffraction (XRD) technique. The obtained results showed that milled surfaces have a homogeneous texture with embedded abrasive particles and high surface roughness. AWJ process introduced high compressive residual stresses with similar order of level in both directions $(X$ and $Y)$. In addition, it was observed that jet pressure is the most influencing parameter on roughness and depth of cut, whilst traverse speed and step-over distance had a significant effect on the residual stress. Based on the experimental analysis, an empirical model to predict the depth of cut was proposed. The validation of the proposed model has shown around 5\% error in the predicted and actual pocket depth.
\end{abstract}

Keywords AWJ $\cdot$ Inconel $718 \cdot$ Roughness $\cdot$ Topography $\cdot$ Depth of cut $\cdot$ Residual stresses

\section{Introduction}

Nickel-based super alloys are widely used for aircraft engines, gas turbines, and in industries like petrochemical and oil refineries. Inconel 718 (IN718) is a precipitation hardened nickel-based super-alloy. The most important properties of IN718 are high strength at elevated temperatures, good corrosion resistance, and high hardness [1,2]. The retention of its properties during machining combined with its poor thermal conductivity makes Inconel 718 difficult to machine by conventional machining processes [1].

Several studies dealing with the influence of conventional machining on surface integrity of IN718 reports problems caused by the interaction of the cutting tool and the target material due to the mechanical and thermal loads during

Redouane Zitoune redouane.zitoune@iut-tlse3.fr

1 Institut Clément Ader, CNRS UMR 5312, 3 Rue Caroline Aigle, 31400 Toulouse, France

2 Institut Clément Ader, CNRS UMR 5312, Campus Jarlard, 81013 Albi, France machining. These problems include an excessive and rapid tool wear which results in a poor surface quality in form of defects as built-up edges (BUE), tears, cavities, burrs, etc. [3-5]. Other difficulties reported are a distortion in the microstructure of IN718 which could be plastic deformation or recrystallization leading to grain refinement and changes in morphology and orientation of the grain [3, 5-8]. Regarding mechanical state, the investigations report a tensile residual stress state at the surface which then shifts to compressive residual state beneath the surface $[3,5,6,9]$. For a finishmachined surface, a tensile residual stress has a detrimental impact from a fatigue loading perspective where it is preferred to have a compressive residual stress state [6]. In order to reduce these topographical, metallurgical and mechanical alterations of the target material after conventional machining, studies have used lubrication $[4,5,10]$; however, this practice is not always effective and has a negative environmental impact. In fact, abrasive water jet (AWJ) machining process provides an alternative to mitigate difficulty in IN718 machining. AWJ seems to be more relevant than conventional process from the point of view of microstructure because of conventional machining induces higher and deeper strainhardening and damage than AWJ [6]. AWJ is a 
nonconventional machining process, which uses highpressure water forced through a nozzle and mixed with abrasive grit particles and directed towards a workpiece as a highvelocity jet focused to erode a desired material. Originally, AWJ was developed for through cutting operations of difficult-to-cut materials by conventional machining processes; whilst AWJ for milling process (controlled-depth) has been less developed [11-13]. The main advantages of AWJ machining are minimized heat affected zone on the workpiece and the versatility to cut any kind of materials from soft to very hard, such as titanium or Inconel $[14,15]$.

AWJ is characterized by a large number of process parameters [16], viz., jet pressure, traverse speed, abrasive flow rate, abrasive grit size, stand-off distance, step-over distance, nozzle diameter, orifice diameter, and length of the focusing tube. These parameters influenced the characteristics of the machined surface, for example, in the work conducted by previous studies $[17,18]$, when machining stainless steel, authors proved that the impact of abrasive flow rate as well as the vibration phenomenon that occur during the cutting process affect the machining quality. It was clearly noticed that the poor machining quality occurs when machining is conducted at high transverse speed and at higher absolute values of material vibrations [18]. In addition, if we refer to the work of [14], it was shown that the most influential parameters on the surface topography and microstructural or mechanical characteristics are jet pressure, traverse speed, stand-off distance and abrasive flow rate. In addition, in the works conducted by Flower et al. and Gupta et al. $[13,14]$ it was shown that the increase in abrasive particle size favors the increase in the material removal rate; however, it leads to degradation of machining quality giving a very poor surface roughness. In fact, to counter this problem, the works conducted by Xavier et al. and Hejjaji et al. [19, 20] recommend a medium mesh size of (\#120) abrasive particles to strike a balance between surface quality and material removal rate.

The availability of literature on the influence of the AWJM parameters on the surface characteristics after machining IN718 is limited. The investigation by Bhandarkar et al. [21] focuses on characterizing pockets milled by AWJ in order to optimize process parameters for pocket dimensions and the average surface roughness $(R a)$. In their work, it was mentioned that the optimal machining parameters to achieve the requested geometry of the depth pocket were a jet pressure of $140 \mathrm{MPa}$ and transverse speed of $1 \mathrm{~m} / \mathrm{min}$. In addition, it was mentioned that the average roughness of the machined surface decreases when machining is conducted at lower pressure and at higher traverse speed. In the experimental work conducted by Rivero et al. [22], it was shown that the direction of milling (tool path) does not have any effect on the surface roughness. It was also reported by the same authors that the main parameters responsible of the surface roughness are the jet pressure, the abrasive flow rate and the stand-off distance. However, the stand-off distance showed a more impact on the roughness values compared to the jet pressure and the transverse speed. In fact, it was shown that machining with a stand-off distance of $10 \mathrm{~mm}$ allowed to obtain a small roughness and less embedded particles on the machined surface compared to the case of machining with high stand-off distance. Unfortunately, milling with a small stand of distance $(10 \mathrm{~mm})$ cannot be possible when workpiece has complex features like concave/convex curvature. In this case of machining, advanced tool compensation needs to be programmed; to avoid this issue, Cenac et al. [23] recommend using of stand-off distance of $100 \mathrm{~mm}$ when machining fuselage parts of aircrafts.

Holmberg et al. [6] studied a comparison of the machinability of Inconel alloy 718 during milling with different processes: conventional milling, electron discharge machining $(\mathrm{EDM})$, laser, and AWJ. The comparison has been performed with only one milling condition for each machining process. Indeed, for AWJ they used a pressure of $380 \mathrm{MPa}$ and $0.11 \mathrm{~m} /$ min of traverse speed, that produced highly desirable surface with low surface roughness $(S a=1.8 \mu \mathrm{m})$ and high compressive residual stress up to $-700 \mathrm{MPa}$ at the surface. However, no information is available about the influence of the parameters of AWJ process on the residual stress when machining Inconel. In another work, Escobar-Palafox et al. [24] investigated pocket milling of IN718 in terms of geometry and depth of cut when using different process parameters, including low pressures below $105 \mathrm{MPa}$, traverse speed between 0.016 and $0.08 \mathrm{~m} / \mathrm{min}$ and step-over distance from 0.5 to $0.8 \mathrm{~mm}$. They showed that the jet pressure is the main parameter influencing the depth of cut. However, the influence of the jet pressure on the depth of cut exhibits nonlinear behavior. Further, when lower traverse speed is used, higher abrasive flow rate is required to achieve deeper depth of cut. Unfortunately, using higher abrasive flowrate favors the augmentation of the surface roughness $[13,14]$. In fact, this phenomenon can be explained by the fact that when machining is conducted with small transverse speed the kinetic energy carried by the particles to the work piece is higher than the case of machining with high transverse speed. Similar results have been obtained by Ay et al. [25] during their investigation on the effect of traverse speed on kerf shape by cutting a single slot. In fact, it was concluded that lower traverse speed generates deeper depth of cut and wider kerf because at lower traverse speeds more time is needed for cutting, leading to increased jet overlapping on the target material.

The present work focuses on the influence of the AWJ process parameters on the roughness, surface topographical characteristics, depth of cut and residual stresses during milling of IN718. For this, a full factorial experiment with 3 factors (viz., water jet pressure, traverse speed and step-over distance) at 3 levels was adopted for investigation. After machining, the roughness, depth of cut and residual stresses of the 
specimens have been measured and characterized as a function of the machining parameters. In addition, an empirical model is proposed for the prediction of the depth of cut, which is based on the total pocket depth.

\section{Experimental procedure}

The material used is this study was annealed Inconel alloy 718 with an ultimate tensile strength of $903 \mathrm{MPa}$, a yield strength of $450 \mathrm{MPa}$, and an elongation of $50 \%$. The chemical content of the material is given in Table 1. Full factorial experiments were performed on specimens of size $180 \mathrm{~mm} \times 20 \mathrm{~mm} \times 3.71 \mathrm{~mm}$ on an AWJ Machine Flow MACH4-C. The details of some major machine components are as follows, orifice diameter of $0.33 \mathrm{~mm}$, a focusing tube length of $76 \mathrm{~mm}$ and nozzle diameter of $1.016 \mathrm{~mm}$. Also, abrasive garnet of mesh size \#120 is used in the present work. As mentioned in the introduction, machining with the mesh size of \#120 favors an acceptable surface roughness without compromising in material removal rate (machining time). Figure 1 shows the experimental setup for milling by AWJ. All experiments are carried out keeping a constant stand-off distance and abrasive flow rate. Each test sample was milled in order to create four blind pockets of $20 \mathrm{~mm}$ of length each spaced $20 \mathrm{~mm}$ following a raster scan tool path (Fig. 2a) and keeping jet direction changes outside the workpiece to avoid acceleration and deceleration effects on milling. Jet pressure, traverse, speed and step-over distance parameters were varied at three different levels in order to accomplish a total experimental design of 27 experiments. The process parameters used to perform the machining are specified in Table 2. Each experiment was repeated for four times by creating four pockets with same set of machining parameters (Fig. 2b) in order to ensure good reliability of the process.

The characterization of the machined surface was done in terms of surface roughness, pocket depth, and residual stress. The roughness measurements of all pockets were performed using an Alicona Infinite Focus 3D optical profilometer over a surface area of $5.7 \mathrm{~mm} \times 5.7 \mathrm{~mm}$ at the center of each machined pocket (Fig. 2c) with a vertical and lateral resolution of $0.10 \mu \mathrm{m}$ and $4.00 \mu \mathrm{m}$ respectively. In order to correctly treat the measured data, three steps were performed before the surface roughness analysis. First, the data set was treated for leveling to remove measurement errors due to parallelism problem between profilometer sensor and the target sample.

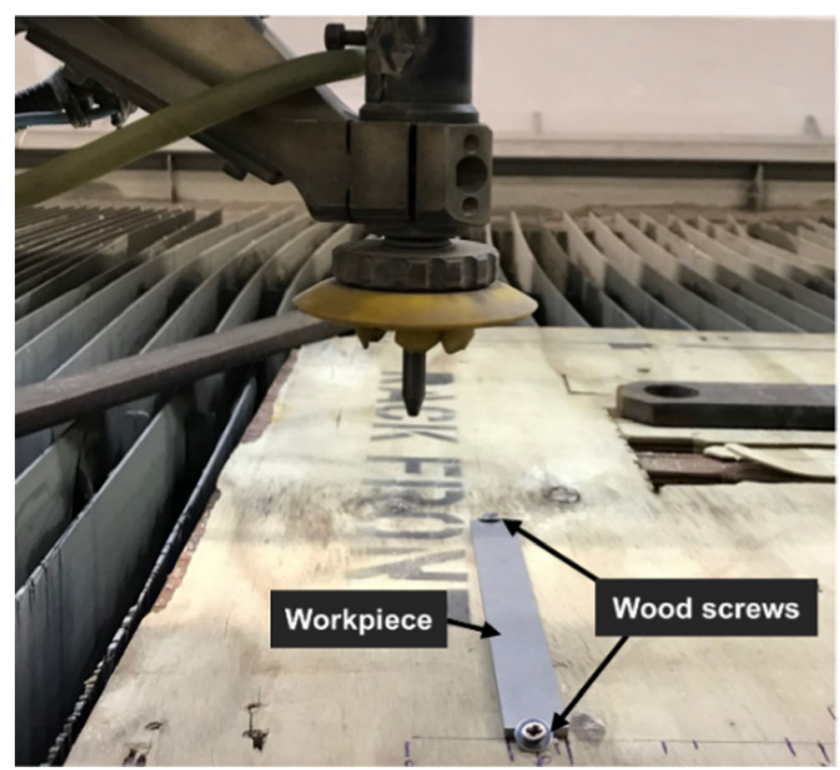

Fig. 1 Experimental setup for AWJ milling

Then, the unmeasured points of the scanned surfaces were filled by interpolation method. Finally, the scanned surfaces were cropped to a size of $5 \times 5 \mathrm{~mm}$ in order to remove measurement errors due to edge effects. No filter was applied for treating the $3 \mathrm{D}$ data set.

The pocket depth of each machined pocket was measured using an Altisurf ( $) 520 \mathrm{v}$ microscope. The pocket profile was measured by scanning a profile of $40 \mathrm{~mm} \times 2 \mathrm{~mm}$ in longitudinal direction starting at a point on non-machined surface (1) to a final point outside the milled pocket surface (2) as shown in Fig. 2c, using vertical resolution of $0.5 \mu \mathrm{m}$ and a lateral resolution of $10 \mu \mathrm{m}$. In order to avoid errors in depth measurement, the data set was leveled using least plane squares method keeping the measurement starting and ending points as reference. In addition, a Gaussian filter was applied to the measured data in order to remove the outliers.

Residual stress measurements were performed by means of $\mathrm{X}$-ray diffraction (XRD) technique. This method was used to estimate the magnitude of the macro-residual stresses on the middle of the machined pocket. Residual stresses were evaluated along the longitudinal direction of the specimen $\left(\sigma_{11}\right)$ and parallel to feed direction $\left(\sigma_{22}\right)$ (Fig. 3b). The XRD measurements were performed using 6-axis XRayBot ${ }^{\circledR}$ apparatus equipped with a goniometer with a pure $\mathrm{Si}$ solid state detector (Fig. 3a). Table 3 shows the default analysis parameters for Inconel 718. The spot was passed through a circular hole of

Table 1 Chemical composition of the investigated Inconel 718 specimens

\begin{tabular}{lllllllllllllllll}
\hline $\mathrm{Ni}(\%)$ & $\mathrm{Cr}(\%)$ & $\mathrm{Fe}(\%)$ & $\mathrm{Nb}(\%)$ & $\mathrm{Mo}(\%)$ & $\mathrm{Ti}(\%)$ & $\mathrm{Al}(\%)$ & $\mathrm{Co}(\%)$ & $\mathrm{C}(\%)$ & $\mathrm{Mn}(\%)$ & $\mathrm{Si}(\%)$ & $\mathrm{S}(\%)$ & $\mathrm{P}(\%)$ & $\mathrm{B}(\%)$ & $\mathrm{Cu}(\%)$ & $\mathrm{Ta}(\%)$ \\
\hline 53.47 & 18.28 & 18.2 & 5.06 & 2.98 & 0.96 & 0.51 & 0.17 & 0.03 & 0.09 & 0.08 & 0.0003 & 0.007 & 0.001 & 0.06 & 0.01 \\
\hline
\end{tabular}


(a)

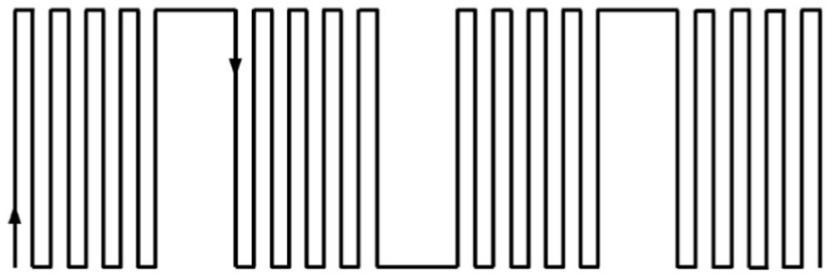

(b)

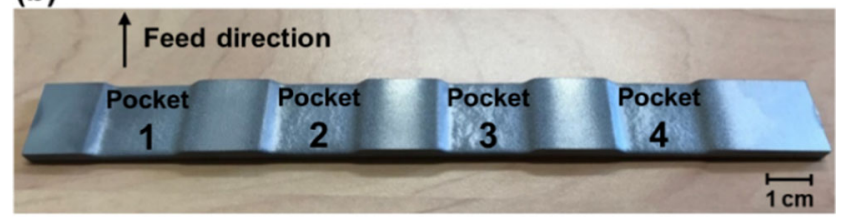

(c)

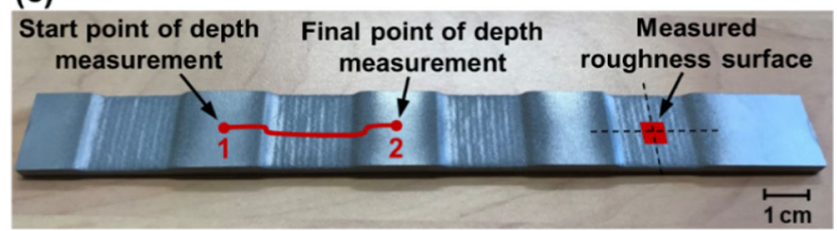

Fig. 2 (a) Tool path; (b) sample machined at $P=250 \mathrm{MPa}, f=1 \mathrm{~m} / \mathrm{min}$, and $S T D=0.5 \mathrm{~mm}$; (c) location of pocket depth and roughness measurements of the pocket 2 and the pocket 4 , respectively, of the specimen milled at $P=300 \mathrm{MPa}, f=0.5 \mathrm{~m} / \mathrm{min}$ and $S T D=1.5 \mathrm{~mm}$

$5 \mathrm{~mm}$ in diameter without collimator. Residual stresses data were computed by StressDiff® software based on the conventional $\sin ^{2}(\Psi)$ method.

\section{Results}

The results of pocket depth, roughness, and residual stress are the average obtained from the measurements made on four pockets with same machining parameters. The specimens $T 10$ and $T 19$ were not considered for the analysis as the specimens were destroyed upon milling, as the milled depth was higher than the thickness of the workpiece $(3.71 \mathrm{~mm})$.

\subsection{Surface roughness and topography}

Figures 4 and 5 show experimental results in terms of machining parameters and average surface roughness $(\mathrm{Sa})$. The

Table 2 AWJ milling parameters

\begin{tabular}{lll}
\hline Parameter & Setting & Unit \\
\hline Pressure (P) & $200,250,300$ & $\mathrm{MPa}$ \\
Traverse speed (f) & $0.5,1,1.5$ & $\mathrm{~m} / \mathrm{min}$ \\
Step-over distance (STD) & $0.5,1,1.5$ & $\mathrm{~mm}$ \\
Stand-off distance & 100 & $\mathrm{~mm}$ \\
Abrasive flow rate & 0.18 & $\mathrm{~kg} / \mathrm{min}$ \\
\hline
\end{tabular}

(a)

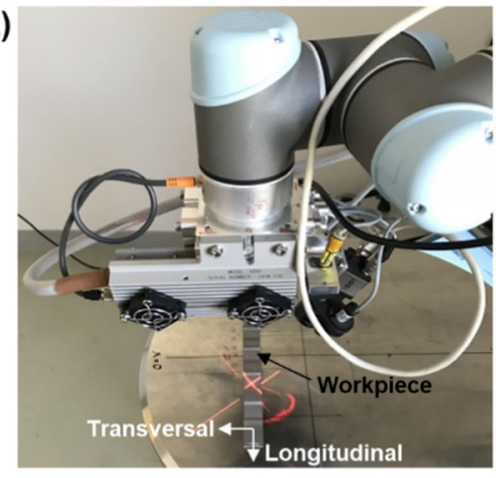

(b)

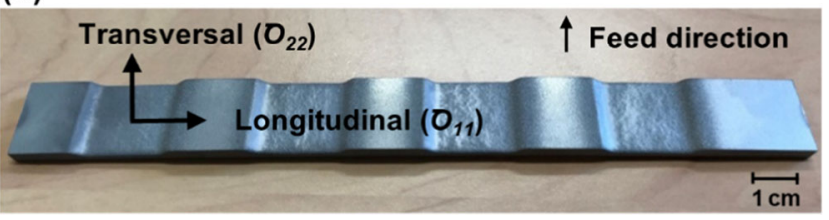

Fig. 3 (a) Setup for the residual stress measurements; (b) residual stress measurement directions

roughness parameter $(\mathrm{Sa})$ is typically used to evaluate surface roughness of an area. The results show relatively high roughness compared to roughness that can be obtained when conventional process is used $[3,6]$. In fact, when milling is conducted with conventional cutting tool, the average roughness $S a$ reported is around $1 \mu \mathrm{m}$ when machining with new tool and up to $3.9 \mu \mathrm{m}$ when machining with a worn tool.

The effect of the jet pressure on the surface roughness when varying traverse speed and step-over distance is presented in the Fig. 4. The results show that as pressure and step-over distances are increased, the surface roughness also increases. In addition, an increase in pressure with a decrease in traverse speed leads to an increase in surface roughness (Fig. 4a). The fact that that roughness increases with increasing pressure is because at higher pressures, the abrasive particles produce deeper indentations as they possess higher kinetic energy, in the target material and consequently rougher surfaces. This effect was also seen by Rivero et al. [22] when milling alloy 718 by AWJ at different conditions of pressure, stand-off distance, abrasive flow rate and traverse speed.

Table 3 XRD Inconel

718 settings

.

\begin{tabular}{ll}
\hline Choice of radiation source & $\mathrm{Mn}$ \\
Filter & $\mathrm{Cr}$ \\
Fluorescence & $/$ \\
Diffraction peak & $\{311\}$ \\
Voltage & $20 \mathrm{kV}$ \\
Current & $1 \mathrm{~mA}$ \\
$2 \theta_{0}$ & $150^{\circ}$ \\
Acquisition time & $120 \mathrm{~s}$ \\
Angle of incidence $\psi$ & 19 \\
\hline
\end{tabular}


Fig. 4 Effect of the pressure on surface roughness at (a) different traverse speed and (b) different step-over distance (a)

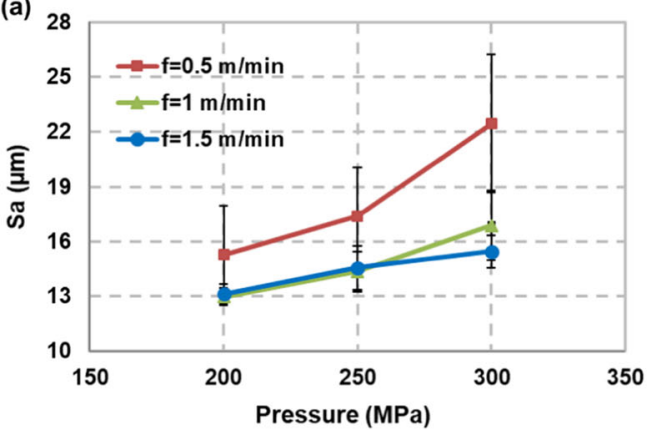

(b)

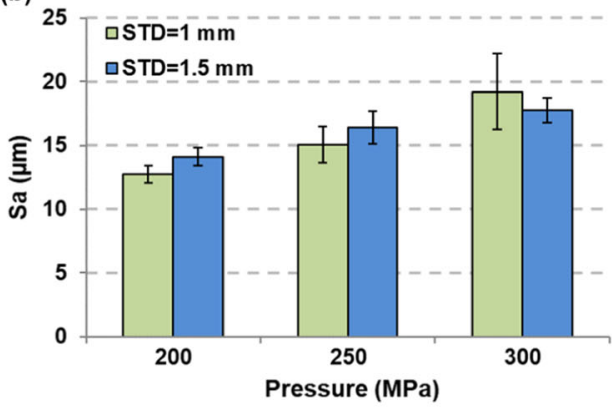

On the other hand, when the traverse speed increases, the surface roughness tends to decrease (Fig. 5). The surface roughness shows a strong decrease when traverse speed increases from $0.5 \mathrm{~m} / \mathrm{min}$ to $1 \mathrm{~m} / \mathrm{min}$. However, the increase of traverse speed beyond $1 \mathrm{~m} / \mathrm{min}$ the reduction of surface roughness is negligible. This is due to the fact that the effect of transverse speed on the surface roughness is coupled with the effect of the jet pressure. Hence, for speeds superior to $1 \mathrm{~m} / \mathrm{min}$ the effect on roughness is less pronounced at low pressures compared to roughness at high pressure (300 MPa), where a clear decreasing effect is seen (Fig. 5b). The traverse speeds chosen in this study corresponds to low velocities. In comparison, a study using high traverse speeds $(5-15 \mathrm{~m} / \mathrm{min})$, revels no clear effect of traverse speed on surface roughness [22], this investigation states that the size, shape, and velocity impact of the abrasive particle is independent to the traverse speed. Conversely, a study performed by Fowler et al. [13] during milling titanium alloys in a single pass using five different abrasives and three different traverse speeds $(1.8,4.8,9.96 \mathrm{~m} / \mathrm{min})$ observed that a decrease in traverse speed generates lower surface roughness similar to what is seen in this study.

In the case of $S T D$, there is no clear effect of step-over distance on surface roughness regardless of the jet pressure (Fig. 6a). However, it can be seen that surface roughness slightly increases when step-over distance increases for all pressures only at $1.5 \mathrm{~m} / \mathrm{min}$ of traverse speed (Fig. 6b). This increase in surface roughness is a maximum of $1 \mu \mathrm{m}$ when increasing step-over distance, and up to $3 \mu \mathrm{m}$ when increasing pressure and step-over distance. Since this increase is slight, it could be said that surface roughness remains constant as the pressure and/or step-over distance increase when using traverse speed is $1.5 \mathrm{~m} / \mathrm{min}$. For the other two traverse feed rates of 0.5 and $1 \mathrm{~m} / \mathrm{min}$, there is no clear effect. In any case, it appears that step-over distance parameter have no great impact on surface roughness (Fig. 6).

The milled surface topographies of some samples are presented in Figs. 7, 8, and 9. These samples were milled with different AWJ parameters. Fig. 7 presents the effect of pressure when traverse speed and step-over distance are constant. It is observed that an increase in pressure leads to an increase in craters (size and depth) which will result in higher roughness. Fig. 8 shows the effect of three different traverse speeds on surface topography. It is noticed that the effect of increase in traverse speed generates a machined surface with lower surface roughness. Fig. 9 illustrates the effect of step-over distance for a constant traverse speed and pressure. STD does not seem to have a significant effect on the craters and their morphology.

The different surfaces show a homogeneous texture overall. However, in some machining conditions, the milled tracks along the feed direction can be noticed (Figs. 8a,b and 9c).

Further analysis of the surface microstructure was performed using SEM at 150x magnification in Back Scattered Electron (BSE) mode. Figures 10, 11, and 12 illustrate the aspect of AWJ milled surfaces at different machining conditions. The images clearly show traces of abrasive particles incrusted during machining. The heavy materials like nickel
Fig. 5 Mean effect of traverse speed on surface roughness at (a) different step-over distances and (b) at different water pressures (a)

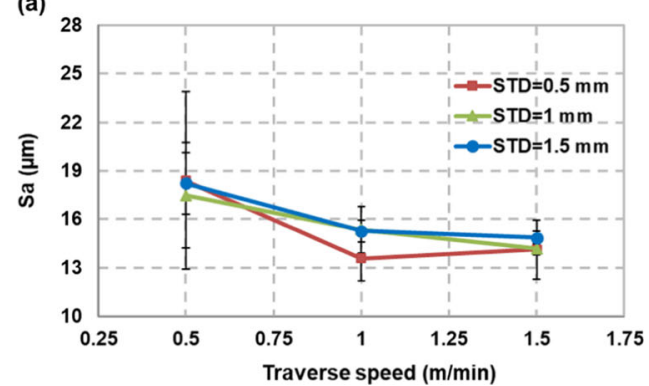

(b)

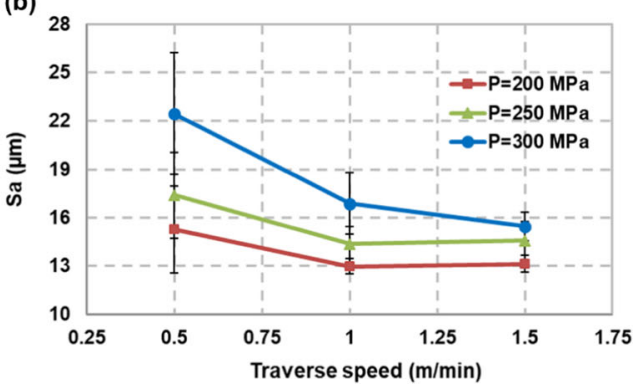


Fig. 6 Effect of step-over distance on surface roughness (a) at different traverse speeds and (b) at different pressures with traverse speed of $1.5 \mathrm{~m} / \mathrm{min}$ (a)

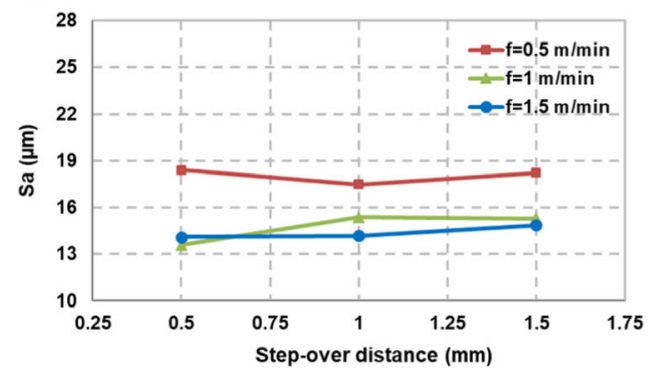

(b)

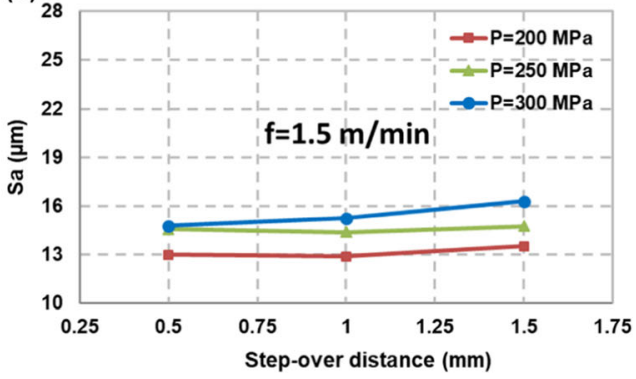

(a)

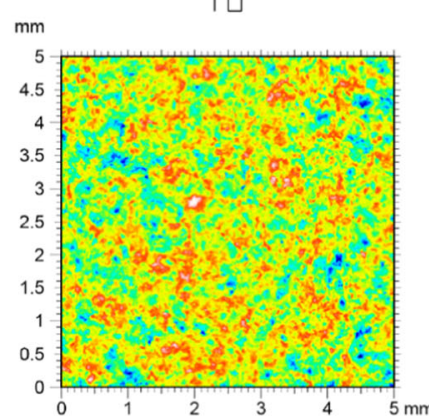

(b)

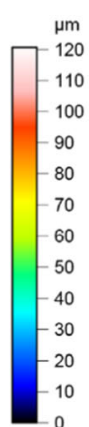

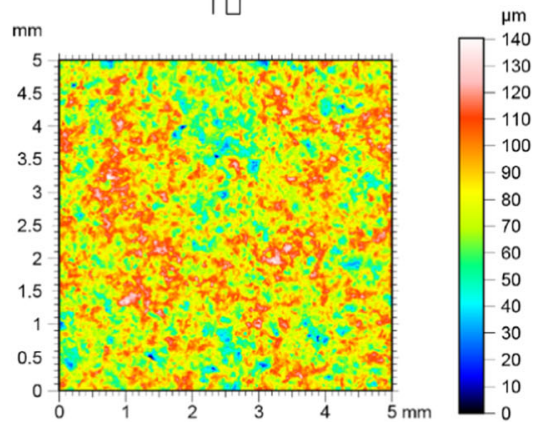

(c)

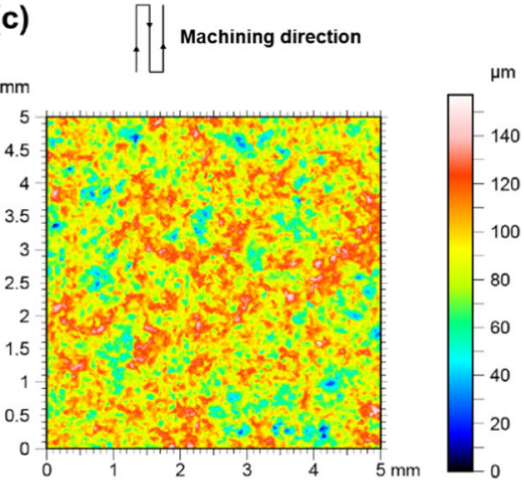

Fig. $73 \mathrm{D}$ views of the milled surfaces by AWJ of samples machined at $f=1.5 \mathrm{~m} / \mathrm{min}, S T D=1 \mathrm{~mm}$ and $P$ of (a) $200 \mathrm{MPa}$, (b) $250 \mathrm{MPa}$, and (c) $300 \mathrm{MPa}$

(a)

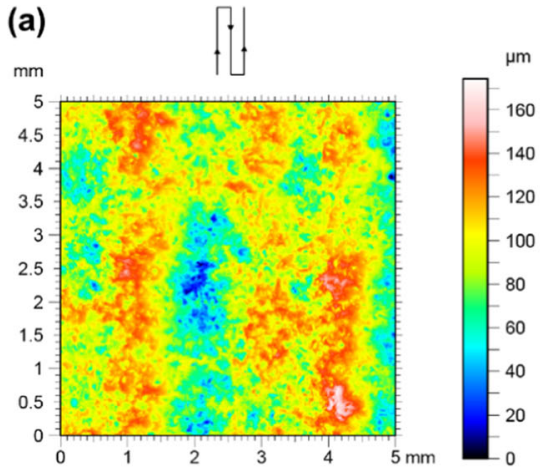

(b)

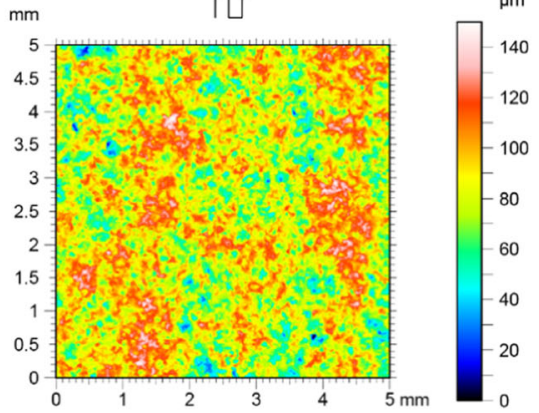

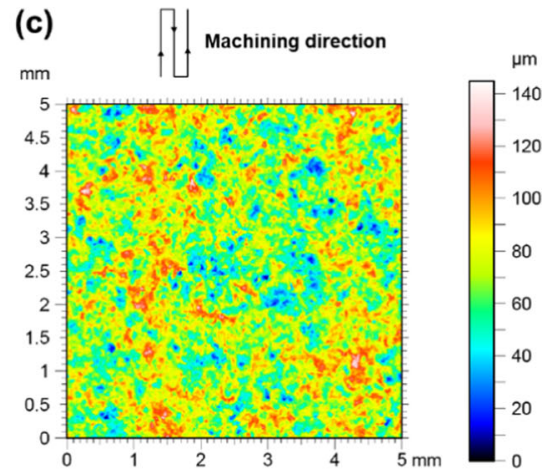

Fig. 8 3D views of the milled surfaces by AWJ of samples machined at $250 \mathrm{MPa}$ of pressure, $S T D=1.5 \mathrm{~mm}$ and (a) $f=0.5 \mathrm{~m} / \mathrm{min} ;(\mathbf{b}) f=1.0 \mathrm{~m} / \mathrm{min}$ and (c) $f=1.5 \mathrm{~m} / \mathrm{min}$

(a)

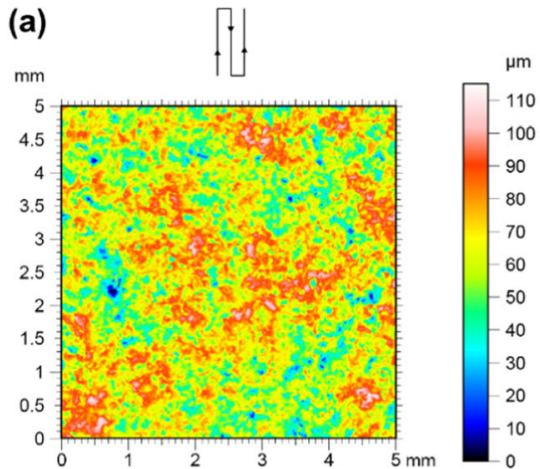

(b)

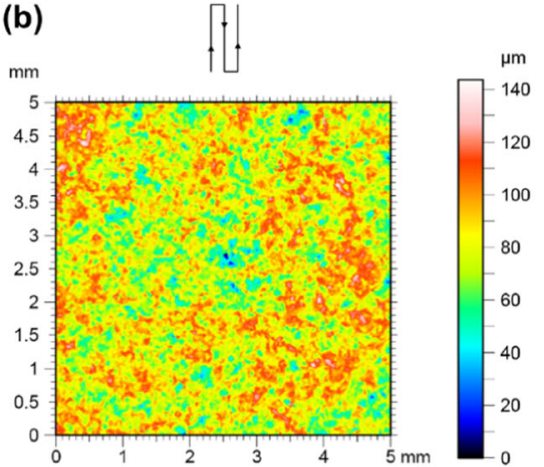

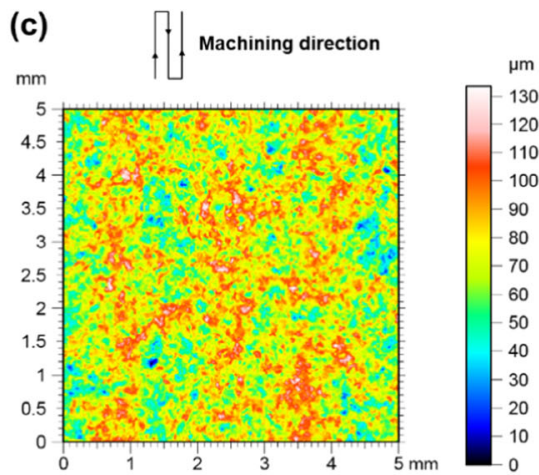

Fig. 9 3D views of the milled surfaces by AWJ of samples machined at $200 \mathrm{MPa}$ of pressure, $f=1.5 \mathrm{~m} / \mathrm{min}, P=200 \mathrm{MPa}$ and (a) $S T D=0.5 \mathrm{~mm}$; (b) $S T D=1 \mathrm{~mm}$ and (c) $S T D=1.5 \mathrm{~m}$ 

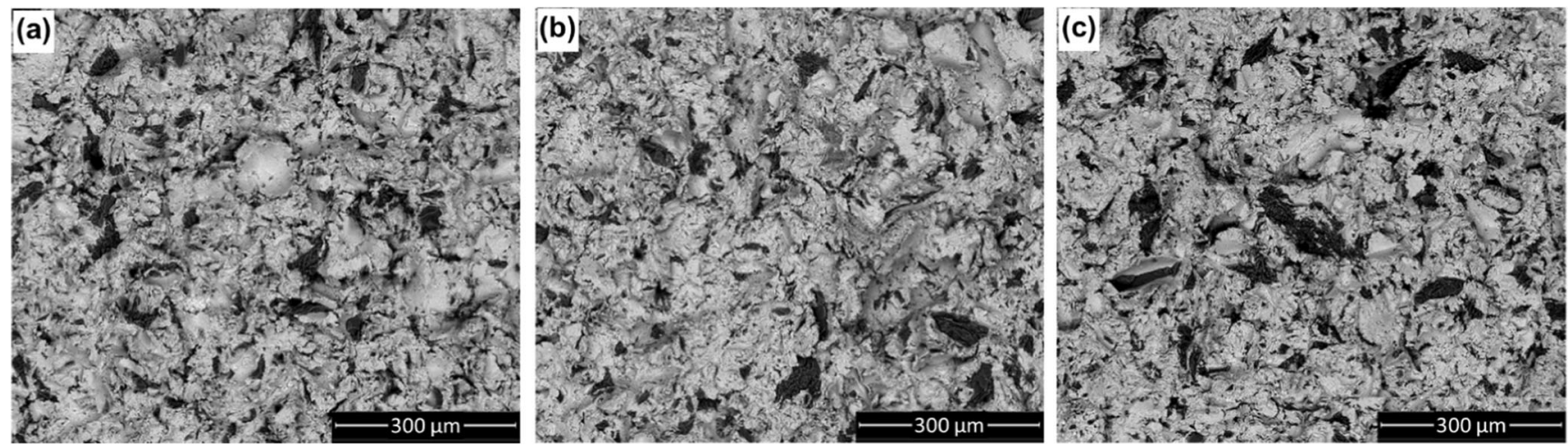

Fig. 10 Micrographs from SEM in $\times 150$ magnification of surfaces machined at $f=1.5 \mathrm{~m} / \mathrm{min}, S T D=1 \mathrm{~mm}$ and $P$ of (a) $200 \mathrm{MPa}$; (b) $250 \mathrm{MPa}$; and (c) $300 \mathrm{MPa}$

are identified in bright contrast, light elements like silicon are represented in grey contrast and dark contrast for the organic particles (composed largely of carbon, hydrogen, and oxygen). In the micrographs were identified silica $\left(\mathrm{SiO}_{2}\right)$ and organic pollutants, which are constituents of the abrasive medium. Figure 10 shows the microstructure of surfaces milled at different pressures; Fig. 11 shows images from surfaces machined at different traverse speed; and Fig. 12 illustrates the micrographs of the surfaces milled using different step-over distances. The surface morphology shows protrusions and valleys on the machined surfaces with plastic deformation due to the impact of the abrasive particles. The presence of these peaks and valleys have detrimental impact on fatigue strength because they favor crack initiation [22]. It is also observed that the material show cased ductile behavior.

Under higher magnification, SEM micrographs show several abrasive particles where large particles are marked with yellow arrows in Fig. 13 which size can reach about $100 \mu \mathrm{m}$ in length. In Fig. 13a is observed a particle identified as silica in two types of embedment, submerged and incrusted. Fig. 13b depicts a dislodgment of material at the crater and several impregnated silica particles, and Fig. 13c shows an organic particle.

\subsection{Pocket depth}

The results summarizing pocket depth with respect to machining parameters are presented in Table 4. Figure 14 depicts the effect of the pressure, the traverse speed, and the step-over distance on the pocket depth. It can be observed that as the pressure is increased, the pocket depth increases (Fig. 14a). This can be explained from the fact that the abrasive particles possess high kinetic energy at high pressure and hence high energy transfer occurs between the particle and the target workpiece material leading to removal of more material. On the other hand, for all three pressures considered, the pocket depth decreases when the traverse speed is increased (Fig. 14a-c).

This effect is due to time of interaction between the water jet and the material surface. Hence, at high traverse speeds, the exposure time between water jet and the workpiece surface is reduced leading to reduced amount of energy transfer from the jet to the workpiece material. This results in removal of lesser material and hence lower milling depth. Similar effect was reported by Gupta et al. [14], when performing pocket milling of SS304 specimens using AWJ.

Finally, an increase in the step-over distance leads to a decrease in pocket depth for all the three pressures tested
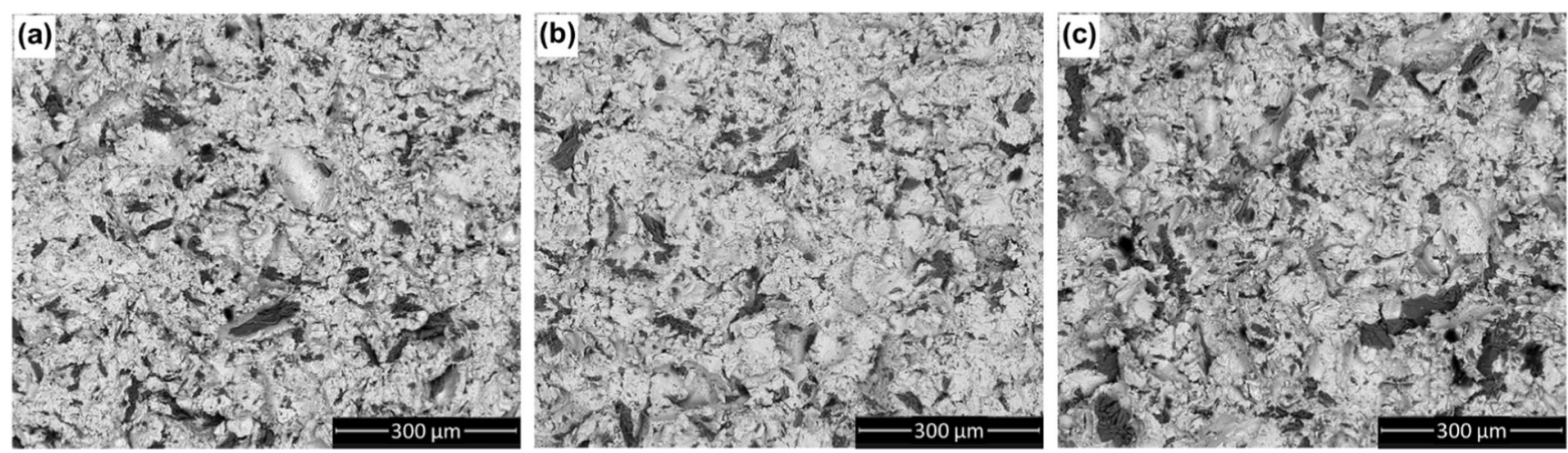

Fig. 11 Micrographs from SEM in $\times 150$ magnification of surfaces machined at $250 \mathrm{MPa}$ of pressure, $S T D=1.5 \mathrm{~mm}$ and (a) $f=0.5 \mathrm{~m} / \mathrm{min} ;(\mathbf{b}) f=$ $1.0 \mathrm{~m} / \mathrm{min}$; and $(\mathbf{c}) f=1.5 \mathrm{~m} / \mathrm{min}$ 

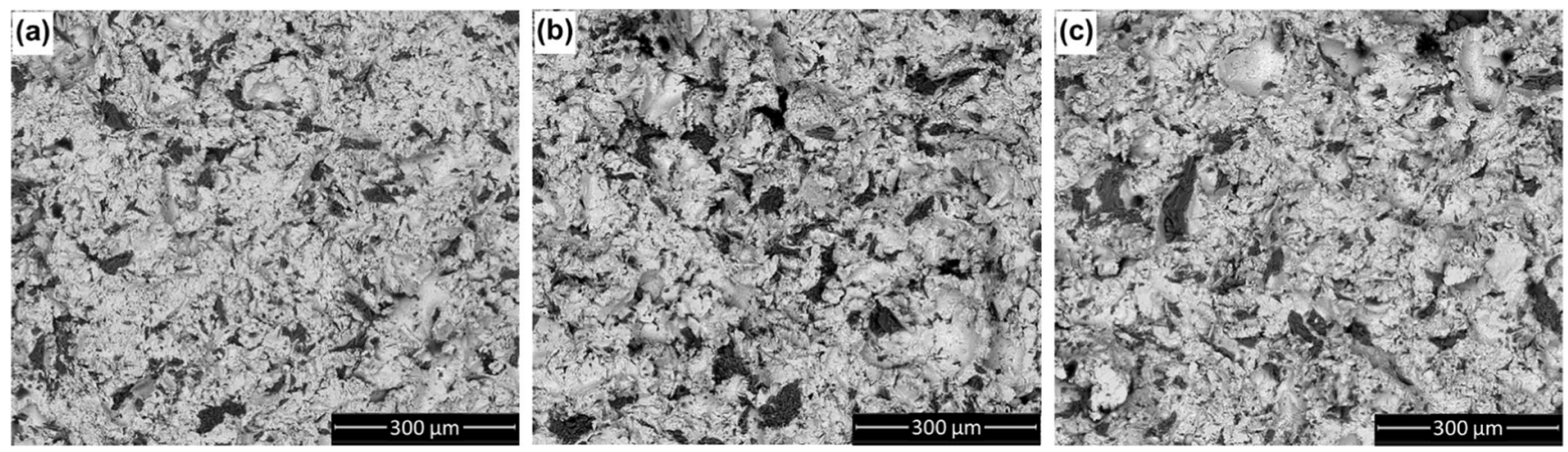

Fig. 12 Micrographs from SEM in $\times 150$ magnification of surfaces machined at $200 \mathrm{MPa}$ of pressure, $f=1.5 \mathrm{~m} / \mathrm{min}$ and (a) $S T D=0.5 \mathrm{~mm}$; (b) $S T D=$ $1 \mathrm{~mm}$; and (c) $S T D=1.5 \mathrm{~m}$

(Fig. 14a-c). When using wide step-over distances, there is smaller overlapping area between one pass jet and the adjacent, resulting in a lesser amount of material removed.

Furthermore, other interesting parameter is the material removal rate $(M R R)$ to evaluate the efficiency of the AWJM. Figure 15 shows that pressure is the parameter that most influences $M R R$. The increase observed of MRR is of approximately $2.5 \mathrm{~mm}^{3} / \mathrm{s}$ each $50 \mathrm{MPa}$ of increase. This phenomenon is due to that at higher pressures, more kinetic energy of the abrasive particles impact on the surface leading to remove more material than at lower pressures. On the other hand, $M R R$ decrease when the traverse speed increases (Fig. 15a). This can be explained considering that for greater speeds, the jet collide less time on the surface allowing eliminate shallower layer of material. In respect to step-over distance, it was found that $M R R$ is slightly largest for smaller step-over distances (Fig. 15b), this is expected due to smaller step-over distance allow for a larger overlapping area that leads to remove more material; however, regardless of the pressure, when increasing $1 \mathrm{~mm}$ in $S T D$, the increase in MRR is very low, about $4 \%$.

From the results of pocket depth obtained experimentally, it can be clearly seen that the three parameters of the machining process (pressure, traverse speed, and step-over distance) have a great influence on the pocket depth. In this context, the prediction of the pocket in function of the machining parameters is an important requirement for the process to be automated and industrialized.

\subsection{Model for the prediction of the depth of cut}

Several studies have proposed analytical models for the prediction of the milled pocket depth when machining composite materials and titanium alloys material $[26,27]$. In fact, the model proposed here for milling IN718 in function of the process parameters of the AWJ (pressure, traverse speed and step-over distance) is based on Eq. 1 from previous literature work [26] related to the machining of composite materials or titanium alloys.

$H=a \cdot P^{b} \cdot f^{c} \cdot S^{d}$

where $a$ is the constant depending on the machinability of the material. $P, f, S$ represent pressure, traverse speed, and stepover distance, respectively. In order to feed the model, 22 values of pocket depth from the experimental data set were
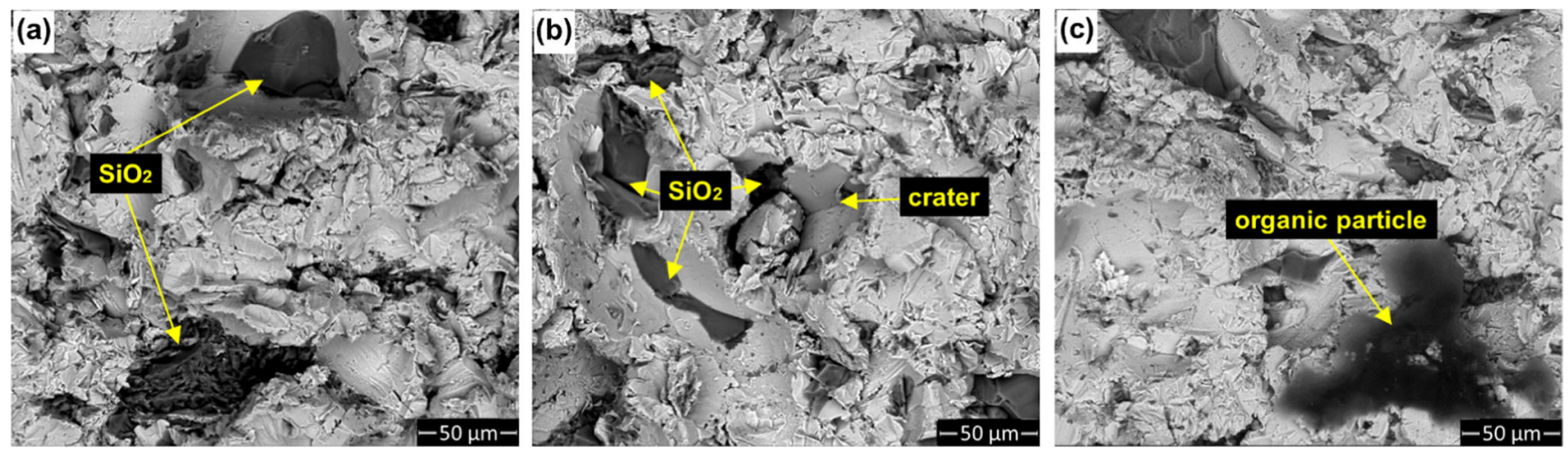

Fig. 13 SEM images of different abrasive particles, (a) silica particles when machining at $P=200 \mathrm{MPa}$, (b) abrasive particles and crater when machining at $P=250 \mathrm{MPa}$, and (c) organic particle at when machining at $P=200 \mathrm{MPa}$ 
Table 4 Variable input parameters and pocket depth output parameters

\begin{tabular}{|c|c|c|c|c|c|}
\hline Exp. No. & $P$ & $f$ & STD & Depth & Std Dev \\
\hline $\mathrm{T} 1$ & 200 & 0.5 & 0.5 & 2.53 & 0.09 \\
\hline $\mathrm{T} 2$ & 200 & 0.5 & 1 & 1.22 & 0.01 \\
\hline $\mathrm{T} 3$ & 200 & 0.5 & 1.5 & 0.80 & 0.01 \\
\hline $\mathrm{T} 4$ & 200 & 1 & 0.5 & 1.23 & 0.02 \\
\hline T5 & 200 & 1 & 1 & 0.59 & 0.01 \\
\hline T6 & 200 & 1 & 1.5 & 0.39 & 0.01 \\
\hline $\mathrm{T} 7$ & 200 & 1.5 & 0.5 & 0.80 & 0.00 \\
\hline $\mathrm{T} 8$ & 200 & 1.5 & 1 & 0.39 & 0.01 \\
\hline T9 & 200 & 1.5 & 1.5 & 0.26 & 0.01 \\
\hline $\mathrm{T} 10$ & 250 & 0.5 & 0.5 & - & - \\
\hline $\mathrm{T} 11$ & 250 & 0.5 & 1 & 1.56 & 0.02 \\
\hline $\mathrm{T} 12$ & 250 & 0.5 & 1.5 & 1.03 & 0.02 \\
\hline $\mathrm{T} 13$ & 250 & 1 & 0.5 & 1.58 & 0.02 \\
\hline T14 & 250 & 1 & 1 & 0.75 & 0.01 \\
\hline T15 & 250 & 1 & 1.5 & 0.49 & 0.00 \\
\hline T16 & 250 & 1.5 & 0.5 & 1.01 & 0.03 \\
\hline T17 & 250 & 1.5 & 1 & 0.49 & 0.00 \\
\hline T18 & 250 & 1.5 & 1.5 & 0.32 & 0.01 \\
\hline T19 & 300 & 0.5 & 0.5 & - & - \\
\hline $\mathrm{T} 20$ & 300 & 0.5 & 1 & 1.90 & 0.02 \\
\hline $\mathrm{T} 21$ & 300 & 0.5 & 1.5 & 1.24 & 0.02 \\
\hline $\mathrm{T} 22$ & 300 & 1 & 0.5 & 1.88 & 0.05 \\
\hline $\mathrm{T} 23$ & 300 & 1 & 1 & 0.89 & 0.01 \\
\hline $\mathrm{T} 24$ & 300 & 1 & 1.5 & 0.58 & 0.00 \\
\hline $\mathrm{T} 25$ & 300 & 1.5 & 0.5 & 1.20 & 0.01 \\
\hline T26 & 300 & 1.5 & 1 & 0.57 & 0.01 \\
\hline T27 & 300 & 1.5 & 1.5 & 0.38 & 0.00 \\
\hline
\end{tabular}

P (MPa), f (m/min), STD (mm), Depth (mm)

considered, and the three remaining results were set apart for the model validation. The constants $a, b, c$ and $d$ were identified by a least-squares algorithm. After computing, the resulting constants are presented in Eq. 2.

$H=5.25 \times 10^{-4} \cdot P^{1.306} \cdot f^{-1.057} \cdot S^{-1.052}$.

From the power of coefficients, it can be seen that the jet pressure parameter has the highest influence on the depth of cut, following by traverse speed and step-over distance. This model correlates well with measured data, as can be seen in Fig. 16a, with a coefficient of correlation of 0.9996 . Furthermore, the model predicts well the pocket depths, as shown in the comparison between experimental depths and theoretical values (Fig. 16b). This model resulted with a maximum uncertainty of $3.9 \%$ for $T 26$ (which was machined at $P=300 \mathrm{MPa}$ ), where the predicted value is overestimated. The second largest difference between experimental and predicted values was of $3.43 \%$ for $T 9$, the shallowest pocket depth milled at $200 \mathrm{MPa}$. For the deepest pocket $T 1$, which was machined at $200 \mathrm{MPa}$, the uncertainty was $0.59 \%$, which is a low variation when high pocket depth is considered. For the specimen set machined at $250 \mathrm{MPa}, T 18$ presented the mayor relative difference about $1.97 \%$. Moreover, it is noted that for some of the largest differences between predicted and experimental values were for specimens milled at $300 \mathrm{MPa}$.

Thus, this model fits well with experimental depths of cut, which means that the low difference obtained are mainly due to the material behavior and measurement errors.

\subsection{Residual stress}

The AWJ milling leads to a compressive residual stress state on the machined surface. The summarized results are presented in Table 5. It was observed that both longitudinal and transverse residual stresses are in compression stress state. The longitudinal residual stress varies between $-291.5 \mathrm{MPa}$
Fig. 14 Effect of the (a) pressure, (b) traverse speed, and (c) stepover distance, on pocket depth (a)

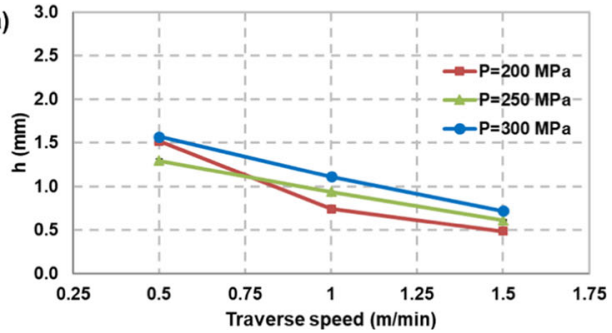

(c)
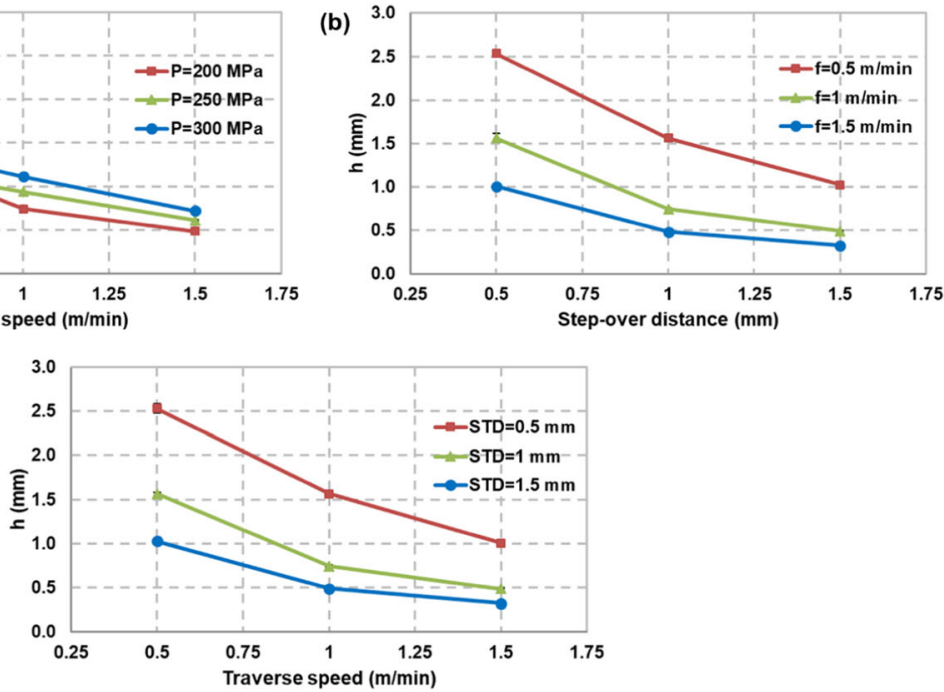
Fig. 15 Effect of (a) the pressure and the traverse speed on the MRR and (b) the pressure and the step-over distance on the MRR

Fig. 16 Graphs of the results of the predicted model (a) experimental values in function of the predicted ones and (b) validation of the model (a)

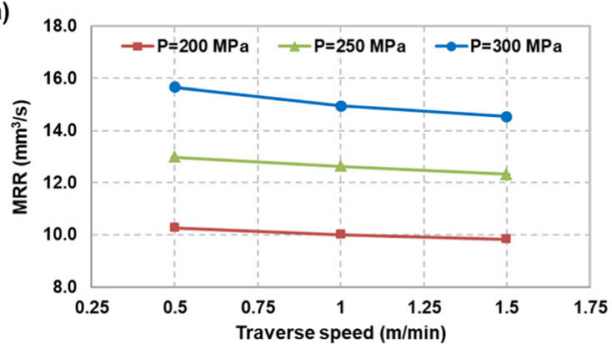

(a)

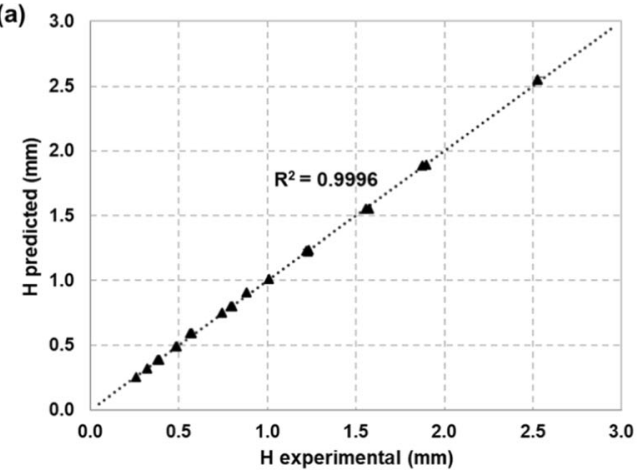

(b)

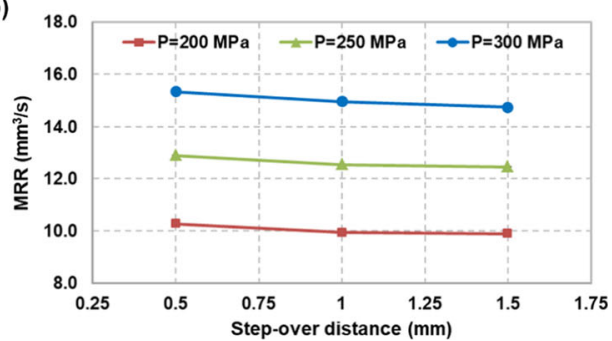

(b)

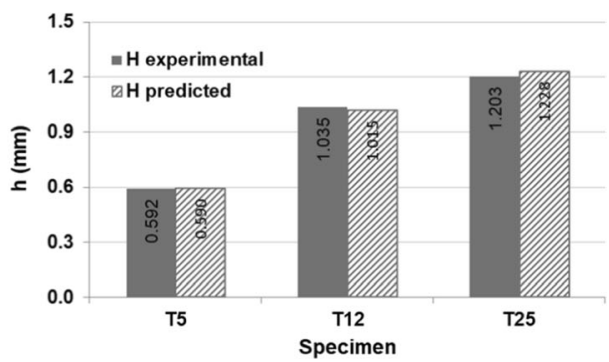

Table 5 Variable input parameters and residual stress output parameters

\begin{tabular}{|c|c|c|c|c|c|c|c|c|c|}
\hline \multirow[b]{2}{*}{ Exp. No. } & \multirow[b]{2}{*}{$P$} & \multirow[b]{2}{*}{$f$} & \multirow[b]{2}{*}{ STD } & \multicolumn{3}{|c|}{ Longitudinal } & \multicolumn{3}{|c|}{ Transverse } \\
\hline & & & & $\sigma_{11}$ & Std Dev & Uncertainty & $\sigma_{22}$ & Std Dev & Uncertainty \\
\hline $\mathrm{T} 1$ & 200 & 0.5 & 0.5 & -533 & 32.14 & 55.75 & -650.75 & 18.39 & 29.25 \\
\hline $\mathrm{T} 2$ & 200 & 0.5 & 1 & -562.5 & 9.29 & 51 & -578.5 & 11.96 & 34 \\
\hline $\mathrm{T} 3$ & 200 & 0.5 & 1.5 & -383.5 & 34.10 & 56 & -364.5 & 18.48 & 30.75 \\
\hline $\mathrm{T} 4$ & 200 & 1 & 0.5 & -515 & 21.74 & 52.25 & -586 & 9.06 & 31.5 \\
\hline T5 & 200 & 1 & 1 & -366.75 & 13.57 & 54.25 & -398.75 & 8.85 & 32.25 \\
\hline T6 & 200 & 1 & 1.5 & -347.25 & 13.23 & 50.5 & -384.25 & 5.38 & 36.75 \\
\hline $\mathrm{T} 7$ & 200 & 1.5 & 0.5 & -402.75 & 10.40 & 50.75 & -429.75 & 27.44 & 35.5 \\
\hline T8 & 200 & 1.5 & 1 & -326.75 & 16.28 & 51.5 & -383.25 & 31.74 & 28 \\
\hline T9 & 200 & 1.5 & 1.5 & -306.5 & 14.25 & 53.75 & -364 & 21.97 & 28.75 \\
\hline $\mathrm{T} 10$ & 250 & 0.5 & 0.5 & - & - & - & - & - & - \\
\hline $\mathrm{T} 11$ & 250 & 0.5 & 1 & -571.25 & 13.15 & 50.5 & -621 & 29.68 & 22.75 \\
\hline $\mathrm{T} 12$ & 250 & 0.5 & 1.5 & -454.25 & 35.12 & 45.25 & -462.25 & 6.65 & 38.5 \\
\hline $\mathrm{T} 13$ & 250 & 1 & 0.5 & -638 & 9.49 & 44.5 & -625 & 20.18 & 28.25 \\
\hline $\mathrm{T} 14$ & 250 & 1 & 1 & -342.5 & 12.56 & 46.25 & -391.75 & 12.15 & 32 \\
\hline $\mathrm{T} 15$ & 250 & 1 & 1.5 & -309.25 & 40.82 & 50.75 & -359.75 & 31.12 & 23.25 \\
\hline T16 & 250 & 1.5 & 0.5 & -407.5 & 17.94 & 46.75 & -460.25 & 26.16 & 25.75 \\
\hline T17 & 250 & 1.5 & 1 & -322.75 & 5.12 & 50 & -351.5 & 15.02 & 27.25 \\
\hline $\mathrm{T} 18$ & 250 & 1.5 & 1.5 & -291.5 & 24.24 & 47.75 & -297.75 & 18.34 & 38 \\
\hline $\mathrm{T} 19$ & 300 & 0.5 & 0.5 & - & - & - & - & - & - \\
\hline $\mathrm{T} 20$ & 300 & 0.5 & 1 & -617 & 45.66 & 60.25 & -650.25 & 16.64 & 33.75 \\
\hline $\mathrm{T} 21$ & 300 & 0.5 & 1.5 & -453.75 & 35.26 & 58 & -459 & 23.71 & 28.75 \\
\hline $\mathrm{T} 22$ & 300 & 1 & 0.5 & -648 & 52.63 & 63.25 & -654.75 & 31.93 & 26.25 \\
\hline $\mathrm{T} 23$ & 300 & 1 & 1 & -341 & 40.21 & 53.75 & -346.5 & 26.11 & 31 \\
\hline $\mathrm{T} 24$ & 300 & 1 & 1.5 & -314.25 & 11.18 & 52.5 & -358 & 30.54 & 35.25 \\
\hline $\mathrm{T} 25$ & 300 & 1.5 & 0.5 & -450.5 & 11.45 & 45.25 & -476 & 32.30 & 28.25 \\
\hline $\mathrm{T} 26$ & 300 & 1.5 & 1 & -311 & 19.24 & 48.5 & -345.25 & 24.80 & 36 \\
\hline $\mathrm{T} 27$ & 300 & 1.5 & 1.5 & -322 & 13.27 & 53.75 & -328.75 & 28.62 & 36.75 \\
\hline
\end{tabular}

P (MPa), f (m/min), STD (mm), $\sigma(\mathrm{MPa})$ 
Fig. 17 Effect of traverse speed and step-over distance at constant pressure on residual stresses along longitudinal and transverse directions (a)

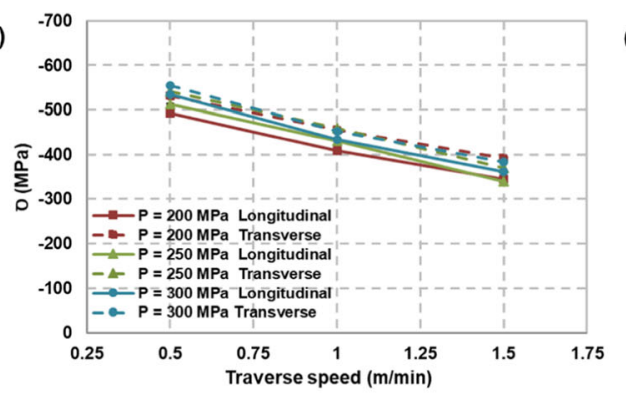

(b)

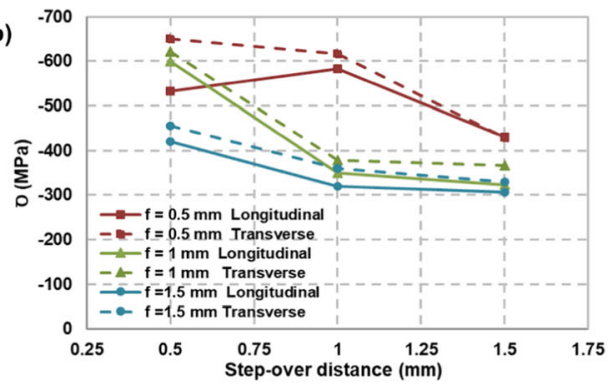

(c)

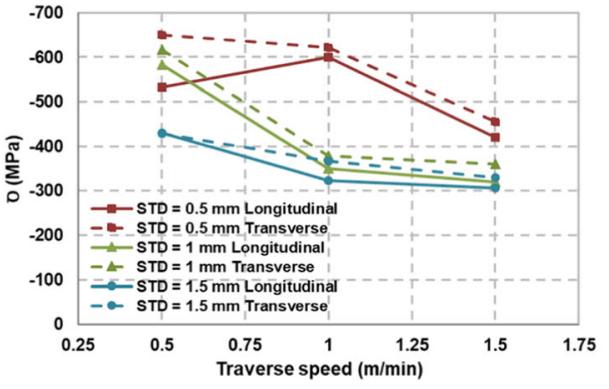

and $-648 \mathrm{MPa}$, the transverse residual stress varies between $-297.75 \mathrm{MPa}$ and $-654.75 \mathrm{MPa}$. It can be noted that the values of the longitudinal and transverse residual stresses are very close. This means that the AWJ process does not generate residual stresses in a particular direction unlike conventional machining. This can be explained by the fact that the AWJ process does not favor a direction as for the flow of material during the material removal in conventional machining [28]. The small difference between longitudinal and traverse residual stress value is due to the effect of the impingement angle of the water jet on the surface owing to the machining direction.

On the other hand, the pressure has no impact on the residual stress state (Fig. 17) in both longitudinal and transverse directions. Nevertheless, residual stresses seem to decrease when increasing traverse speed and step-over distance (Fig. 17). This may be due to the fact that the abrasive particles at higher speeds have less impact on the machine surface due to short exposure time.

Based on the various results obtained in the study, in Table 6, the main characteristics of the machined surface when milling IN718 with AWJ is presented. These results indicate the range of surface integrity values and show the test numbers with which the minimum and maximum results values were obtained.

The evaluation of the effects on surface integrity aspects after AWJ milling in IN718 is also summarized in Table 7.

\section{Conclusions}

In this study, the influence of the AWJ milling parameters, viz., jet pressure, traverse speed and step-over distance on surface roughness, topography, pocket depth, and residual stress when milling Inconel 718 by AWJ were investigated experimentally. The following conclusions can be drawn from the study:

- The surface roughness $(\mathrm{Sa})$ varies from $12.2 \mu \mathrm{m}$ to $24.6 \mu \mathrm{m}$. Surface roughness increases with the increase in pressure but decreases with increasing traverse speed. In addition, the milled surfaces presented a homogeneous texture with embedded abrasive particles. The jet pressure

Table 6 AWJ milling results on different aspects of surface integrity of IN718

\begin{tabular}{|c|c|c|c|c|c|}
\hline \multirow[t]{2}{*}{ Surface integrity } & \multirow[t]{2}{*}{ Surface roughness, $S a(\mu \mathrm{m})$} & \multirow[t]{2}{*}{ Pocket depth, $h(\mathrm{~mm})$} & \multirow[t]{2}{*}{ Material removal rate, $M R R\left(\mathrm{~mm}^{3} / \mathrm{s}\right)$} & \multicolumn{2}{|c|}{ Residual stress (MPa) } \\
\hline & & & & $\sigma_{x x}$ & $\sigma_{y y}$ \\
\hline & $12.23-24.58$ & $0.26-2.53$ & $9.73-15.86$ & -292 to -648 & -298 to -655 \\
\hline Minimal & $\mathrm{T} 4$ & T9 & $\mathrm{T} 8$ & $\mathrm{~T} 18$ & $\mathrm{~T} 18$ \\
\hline Maximal & $\mathrm{T} 20$ & $\mathrm{~T} 1$ & $\mathrm{~T} 20$ & $\mathrm{~T} 22$ & $\mathrm{~T} 22$ \\
\hline
\end{tabular}


Table 7 Effect of AWJ milling parameters on different aspects of surface integrity of IN718

\begin{tabular}{lllll}
\hline Machining parameters & Surface roughness & Pocket depth & Material removal rate & Residual stress \\
\hline$P \uparrow$ & $\uparrow$ & $\uparrow$ & $\uparrow$ & $\approx$ \\
$f \uparrow$ & $\downarrow$ & $\downarrow$ & $\downarrow$ & $\downarrow$ \\
$S T D \uparrow$ & $\downarrow$ & $\uparrow$ & $\downarrow$ \\
$P \uparrow+f \uparrow$ & $\uparrow$ & & \\
$P \uparrow+S T D \uparrow$ & $\uparrow$ & & & \\
$P \uparrow+S T D \downarrow$ & $\uparrow$ & & & $\uparrow$ \\
$f \downarrow+S T D \downarrow$ & & $\uparrow$ & & \\
\hline
\end{tabular}

$\uparrow$ increase, $\downarrow$ decrease, $\uparrow$ no clear effect, $\approx$ almost constant plays an important role in creation of crater defects. The crater size and depth increase with increasing jet pressure.

- The pocket depths vary between $0.26 \mathrm{~mm}$ and $2.53 \mathrm{~mm}$. An increase in pressure leads to an increase in pocket depth, but a decrease was observed when increasing traverse speed and step-over distance.

- A model to predict the pocket depth in function of machining parameters was obtained and was experimentally validated. The model can predict the pocket depth with $96 \%$ of accuracy and a maximum deviation of $5 \%$ between the measured and predicted values.

- AWJ machining produces a high compressive residual stress state for all milled surfaces, which values are very close in both longitudinal and transverse directions (from $-292 \mathrm{MPa}$ to $-655 \mathrm{MPa}$ ), which indicate no effect on residual stress due to the tool path. In addition, the pressure parameter has no effect on residual stresses and the increase of the traverse speed and step-over distance favors the reduction in residual stresses.

- AWJ is a promising process to be used instead of conventional methods for milling IN718, nevertheless, after AWJ machining, the surfaces need to be cleaned to remove embedded abrasive particles, which generates up to $300 \%$ more surface roughness than conventional process.

Acknowledgments The authors gratefully acknowledge the financial support of CONACYT Mexico. The authors also thank S. Le Roux for assistance with surface topography. This project was realized in Clément Ader Institute (Paul Sabatier University of Toulouse 3). The authors wish to thank Xavier Sourd and Sabine Le Roux from Clément Ader Institute for their technical support.

Data and materials availability The dataset generated in this research work is not shared at this point of time. However, the readers can approach the corresponding author if required.

Author contributions All authors have participated in (a) conception, experimentation, analysis, and interpretation of the data; (b) drafting the article or revising it critically for important intellectual content; and (c) approval of the final version.
Funding information This research work was supported by the Mexican Agency of research and Technology (CONACYT).

\section{Declarations}

Ethics approval This manuscript has not been submitted to, nor is under review at, another journal or other publishing venue neither in full nor part of it.

Consent for publication The authors give their consent for the publication of identifiable details, which can include photograph(s) and/or details within the text to be published in the above journal.

Competing interests The authors declare that they have no conflict of interest. The authors certify that they have no affiliations with or involvement in any organization or entity with any financial interest, or nonfinancial interest in the subject matter or materials discussed in this manuscript.

\section{References}

1. Campbell J, Flake C (2011) Manufacturing technology for aerospace structural materials. Elsevier, p 616

2. Bunsch A, Kowalska J, Witkowska M (2012) Influence of die forging parameters on the microstructure and phase composition of Inconel 718 alloy. Arch Metall Mater 57:929-935

3. M'Saoubi R, Larsson T, Outeiro J, Guo Y, Suslov S, Saldana C, Chandrasekar S (2012) Surface integrity analysis of machined Inconel 718 over multiple length scales. CIRP Ann 61:99-102

4. Zhou J, Bushlya V, Avdovic P, Stahl JE (2012) Study of surface quality in high speed turning of Inconel 718 with uncoated and coated CBN tools. Int J Adv Manuf Technol 25:141-151

5. Devillez A, Le Coz G, Dominiak S, Dudzinski D (2011) Dry machining of Inconel 718, workpiece surface integrity. J Mater Process Technol 211:1590-1598

6. Holmberg J, Berglund J, Wretland A, Beno T (2019) Evaluation of surface integrity after high energy machining with EDM, laser beam machining and abrasive water jet machining of alloy 718 . Int J Adv Manuf Technol 100:1575-1591

7. Umbrello D (2013) Investigation of surface integrity in dry machining of Inconel 718. Int J Adv Manuf Technol 69:2183-2190

8. Zhou J, Bushlya V, Peng R, Johansson S, Avdovic P, Stahl J (2011) Effects of tool wear on subsurface deformation of nickel-based superalloy. Procedia Eng 19:407-413 
9. Aspinwall D, Dewes R, Ng E-G, Sage C, Soo S (2007) The influence of cutter orientation and workpiece angle on machinability when high-speed milling Inconel 718 under finishing conditions. Int J Mach Tools Manuf 47:1839-1846

10. Imran M, Mativenga PT, Gholinia A, Withers PJ (2011) Evaluation of surface integrity in micro drilling process for nickel-based superalloy. Int J Adv Manuf Technol 55(5-8):465-476

11. Goutham U, Hasu BS, Chakraverti G, Kanthababu M (2016) Experimental investigation of pocket milling on Inconel 825 using abrasive water jet machining. Int J Curr Eng Technol 6(1):295-302

12. Alberdi A, Rivero A, López de Lacalle L, Etxeberria I, Suárez A (2010) Effect of process parameter on the kerf geometry in abrasive water jet milling. Int J Adv Manuf Technol 51:467-480

13. Fowler G, Pashby I, Shipway P (2009) The effect of particle hardness and shape when abrasive water jet milling titanium alloy Ti6A14V. Wear 266:613-620

14. Gupta T, Ramkumar J, Tandon P, Vyas N (2013) Role of process parameters on pocket milling with Abrasive Water Jet Machining technique. Int J Mech Mechatron Eng 7(10):348-353

15. Alberdi A, Rivero A, López de Lacalle L (2011) Experimental study of the slot overlapping and tool path variation effect in abrasive waterjet milling. J Manuf Sci Eng 133(3):034502-034501

16. Momber AW, Kovacevic R (1998) Principles of abrasive water jet machining. Springer, p 394

17. Hreha P, Radvanská A, Hloch S, Perzel V, Królczyk G, Monková K (2015) Determination of vibration frequency depending on abrasive mass flow rate during abrasive water jet cutting. Int $\mathrm{J}$ Adv Manuf Technol 77(1-4):763-774

18. Hreha P, Radvanská A, Knapcikova L, Królczyk G, Legutko S, Królczyk J, Hloch S, Monka P (2015) Roughness parameters calculation by means of on-line vibration monitoring emerging from AWJ interaction with material. Metrol Meas Syst 22(2):315-326

19. Sourd X, Zitoune R, Hejjaji A, Salem M, Crouzeix L, Lamouche D (2020) Multi-scale analysis of the generated damage when machining pockets of $3 \mathrm{D}$ woven composite for repair applications using abrasive water jet process: Contamination analysis. Compos A: Appl Sci Manuf 139:106118

20. Hejjaji A, Zitoune R, Crouzeix L, Le Roux S, Collombet F (2017) Surface and machining induced damage characterization of abrasive water jet milled carbon/epoxy composite specimens and their impact on tensile behavior. Wear 376:1356-1364

21. Bhandarkar V, Singh V, Gupta TVK (2019) Experimental analysis and characterization of abrasive water jet machining of Inconel 718. Mater Today Proc 23:647-650

22. Rivero A, Alberdi A, Artaza T, Mendia L, Lamikiz A (2018) Surface properties and fatigue failure analysis of alloy 718 surfaces milled by abrasive and plain waterjet. Int J Adv Manuf Technol 94(5-8):2929-2938

23. Cenac F, Zitoune R, Collombet F, Deleris M (2015) Abrasive water-jet milling of aeronautic aluminum 2024-T3. Proc Inst Mech Eng L J Mater Des Appl 229(1):29-37

24. Escobar-Palafox G, Gault R, Ridgway K (2012) Characterisation of abrasive water-jet process for pocket milling in Inconel 718. Procedia CIRP 1:404-408

25. Ay M, Çaydaş U, Ahmet H (2010) Effect of traverse speed on abrasive waterjet machining of age hardened Inconel 718 nickelbased superalloy. Mater Manuf Process 25(10):1160-1165

26. Sourd X, Zitoune R, Crouzeix L, Salem M, Charlas M (2020) New model for the prediction of the machining depth during milling of $3 \mathrm{D}$ woven composite using abrasive waterjet process. Compos Struct 234:111760

27. Bui V, Gilles P, Sultan T, Cohen G, Rubio W (2017) A new cutting depth model with rapid calibration in abrasive water jet machining of titanium alloy. Int J Adv Manuf Technol

28. Cai X, Qin S, Li J, An Q, Chen M (2014) Experimental investigation on surface integrity of end milling nickel-based alloy Inconel 718. Mach Sci Technol 18(1):31-46

Publisher's note Springer Nature remains neutral with regard to jurisdictional claims in published maps and institutional affiliations. 